\title{
Type I interferons regulate inflammatory cell trafficking and macrophage inflammatory protein $1 \alpha$ delivery to the liver
}

\author{
Thais P. Salazar-Mather, Casey A. Lewis, and Christine A. Biron \\ Department of Molecular Microbiology and Immunology, Division of Biology and Medicine, Brown University, \\ Providence, Rhode Island, USA
}

\begin{abstract}
Macrophage inflammatory protein $1 \alpha$ (MIP-1 $\alpha$, CCL3) is critical for liver NK cell inflammation and delivery of IFN- $\gamma$ to mediate downstream protective responses against murine cytomegalovirus (MCMV) infections. This system was used to evaluate the upstream contribution of the type 1 IFNs, IFN- $\alpha / \beta$, in promotion of MIP- $1 \alpha$ production. Mice deficient in IFN- $\alpha / \beta$ functions, as a result of mutation in the receptor for these cytokines (IFN- $\left.\alpha / \beta R^{-}\right)$, were profoundly deficient in MIP-1 $\alpha$ expression and accumulation of NK cells and macrophages in the liver and had increased sensitivity to MCMV infection. The cytokines themselves were responsible for the immunoregulatory effects, since administration of recombinant IFN- $\alpha($ rIFN- $\alpha)$ to immunocompetent mice also induced these changes. IFN- $\alpha / \beta$ was required for NK cell accumulation during infection, and MIP- $1 \alpha$ was required for $\mathrm{NK}$ cell accumulation in response to administered rIFN- $\alpha$. In vivo trafficking assays demonstrated a requirement for IFN- $\alpha / \beta \mathrm{R}$ signaling for leukocyte localization in, and delivery of MIP- $1 \alpha$-producing macrophages to, the liver. These results extend characterization of the cytokine and chemokine cascade required for protection against viral infections in tissues by defining IFN- $\alpha / \beta$-dependent mechanisms promoting MIP-1 $\alpha$ production and the resulting hepatic accumulation of NK cells.
\end{abstract}

J. Clin. Invest. 110:321-330 (2002). doi:10.1172/JCI200215376.

\section{Introduction}

Effective delivery of innate immune mechanisms depends on recruitment of cells to sites of infection. Murine cytomegalovirus (MCMV) infections induce an innate cytokine and chemokine cascade that plays a critical role in inflammation and the balance between life and death. Production of the $\beta$ chemokine macrophage inflammatory protein $1 \alpha$ (MIP-1 $\alpha$ ) in virus-infected livers elicits recruitment of activated NK cells to form distinct inflammatory foci around infected cells (1). Macrophages also migrate to liver, but this trafficking is MIP-1 $\alpha$ independent and mostly localized in sinusoidal cavities (1). The MIP$1 \alpha$-dependent NK cell inflammatory responses result in delivery of IFN- $\gamma$ to liver (2-5), and a downstream consequence of these events is induction of the $\alpha$-chemokine monokine induced by IFN- $\gamma$ (Mig, or CXCL9) (5-7). MIP-1 $\alpha$, NK cell IFN- $\gamma$, and Mig are all critical for survival. Thus, the coordinated responses

Received for publication March 1, 2002, and accepted in revised form June 11, 2002.

Address correspondence to: Thais P. Salazar-Mather, Box G-B629, Brown University, 69 Brown Street, Providence, Rhode Island 02912, USA. Phone: (401) 863-9775;

Fax: (401) 863-1971; E-mail: Thais_Mather@brown.edu. Conflict of interest: No conflict of interest has been declared. Nonstandard abbreviations used: murine cytomegalovirus (MCMV); macrophage inflammatory protein $1 \alpha$ (MIP-1 $1 \alpha$ ); plaque-forming units (PFU); R-phycoerythrin conjugated (R-PE-conjugated); recombinant human IFN- $\alpha \mathrm{A} / \mathrm{D}$ ( $\mathrm{rIFN}-\alpha)$; conditioned media (CM); hematoxylin and eosin (H\&E). initiated by MIP- $1 \alpha$ are needed for optimal antiviral defense against infection in tissues.

The requirement for MIP- $1 \alpha$ appears to be selective during MCMV infection even though chemokine responses can be redundant $(8,9)$. The in vivo cellular and molecular mechanisms promoting MIP- $1 \alpha$ expression in liver have not yet been characterized. Early infection with MCMV induces production of several cytokines, including the type 1 interferons, IFN- $\alpha / \beta(3,10)$. IFN- $\alpha / \beta$ are potent activators of antiviral pathways. They also can, however, mediate numerous immunoregulatory functions and modulate expression of cytokines and cytokine receptors $(11,12)$. Moreover, IFN- $\alpha / \beta$ expression can affect leukocyte trafficking (13-16). During MCMV infection, bone marrow-derived macrophages and NK cells migrate to secondary sites in response to IFN- $\alpha / \beta$ production (16). It is not known whether these leukocyte trafficking events are directly mediated by IFN- $\alpha / \beta$ and/or result from indirect immunoregulatory effects of IFN- $\alpha / \beta$ on chemokine production.

The experiments presented here were undertaken (a) to define IFN- $\alpha / \beta$ roles in defense and regulation of MIP- $1 \alpha$ production and NK cell accumulation, and (b) to identify a mechanism for induction of MIP- $1 \alpha$ expression in tissues during MCMV infection. The results demonstrate that IFN- $\alpha / \beta$ is produced in liver and that IFN- $\alpha / \beta$-mediated effects increase resistance to MCMV. The IFN- $\alpha / \beta$ response is eliciting a number of immunoregulatory events contributing to defense, including promoting MIP- $1 \alpha$ production and accu- 
mulation of NK cells and macrophages in liver. The IFN- $\alpha / \beta$ effects on NK cell accumulation are MIP- $1 \alpha$ dependent, and on MIP- $1 \alpha$ expression are dependent on recruiting MIP- $1 \alpha$-producing macrophages into liver. Taken together, these results provide new insights into IFN- $\alpha / \beta$ functions and demonstrate a unique pathway in regulation of chemokine responses required for localizing innate antiviral defenses.

\section{Methods}

Mice. Specific pathogen-free C57BL/6 and 129/Sv mice were purchased from The Jackson Laboratory (Bar Harbor, Maine, USA) or Taconic Laboratory Animals and Services (Germantown, New York, USA), respectively. Breeding pairs of homozygous MIP- $1 \alpha$ mutants, C57BL/6-MIP-1 $\alpha^{-}$(17), from The Jackson Laboratory were used to establish colonies at Brown University. Mice functionally deficient in IFN- $\alpha / \beta$ as a result of mutation of the receptor, $129-\mathrm{IFN}-\alpha / \beta \mathrm{R}^{-}$(18), were originally obtained from $\mathrm{B} \& \mathrm{~K}$ Universal Ltd. (North Humberside, United Kingdom) but also bred and maintained at Brown University. Male and female mice were used between 5 and 6 weeks of age. Mouse handling and experimental procedures were conducted in accordance with institutional guidelines.

Virus, infections, and in vivo treatment protocols. Stocks of Smith-strain MCMV salivary gland extracts were prepared (2). Infections were initiated on day 0 (uninfected) with $5 \times 10^{4}$ (moderate dose) plaque-forming units (PFU) of MCMV, or when indicated with $1 \times 10^{4}$ (low dose) PFU of MCMV, via the intraperitoneal route. In survival experiments, mice were assessed twice daily. Animals treated in vivo with recombinant human IFN- $\alpha$ A/D (rIFN- $\alpha$ ) (Pestka Biomedical Laboratories, New Brunswick, New Jersey, USA), biologically active in mice, were given three intraperitoneal daily injections of $1 \times 10^{5}$ units in PBS containing $0.1 \%$ BSA. Control animals were given vehicle injections.

Preparation of leukocytes, tissue homogenates, and conditioned media. Liver leukocytes and homogenates were isolated and prepared as previously described $(5,19)$. For generation of leukocyte-conditioned media (leukocyte-CM), cells were suspended in RPMI media (Life Technologies Inc., Rockville, Maryland, USA) containing $5 \% \mathrm{FCS}$, and incubated at $37^{\circ} \mathrm{C}$ for 24 hours. Cellfree supernatants were collected and used in cytokine analyses. Production levels are expressed as ng/g liver in homogenates or as $\mathrm{pg} / \mathrm{million}$ cells in CM.

Flow cytometric analyses. Proportions and numbers of cells were evaluated as reported (5). For NK cell identification in C57BL/ 6 mice, the following antibodies were used: R-phycoerythrin conjugated (R-PE-conjugated) anti-NK1.1 mAb clone PK136 and CyChromeconjugated anti-TCR- $\beta$ chain mAb clone H57-597 (BD PharMingen, San Diego, California, USA). As mice on a 129 background do not express NK1.1, NK cells were also identified with the following antibodies: biotinconjugated anti-pan-NK mAb clone DX5 followed by streptavidin-allophycocyanin (APC), CyC-conjugated
anti-TCR- $\beta$ chain mAb clone H57-597, and R-PE-conjugated anti-CD122 (IL-2 and IL-15 $\beta$ chain receptor) $\mathrm{mAb}$ clone TM $\beta 1$ (BD PharMingen). In the studies presented, cells identified as $\mathrm{DX}^{+}(20)$ were $74-90 \%$ positive for CD122. As NK cells constitutively express CD122, this marker helped to identify the DX $5^{+}$TCR- $\beta-$ NK cells. To distinguish migrating from resident macrophages (21), the following antibodies were used: R-PE-conjugated anti-F4/80 (Serotec Ltd., Kidlington, Oxford, United Kingdom) and allophycocyanin-conjugated anti-CD11b mAb clone M1/70 (BD PharMingen), or biotin-conjugated anti-F4/80 (Serotec) followed by streptavidin-allophycocyanin and FITCconjugated anti-CD11b mAb clone M1/70 (BD PharMingen). The latter antibodies were used to identify macrophages labeled with red fluorescent PKH26 (Sigma-Aldrich, St. Louis, Missouri, USA). Control antibodies not recognizing specific murine determinants (BD PharMingen) were used to correct for background fluorescence and set analyses gates. Totals of at least 20,000-100,000 events per sample were acquired and analyzed using a FACSCalibur (BD Biosciences, Palo Alto, California, USA) and the CellQuest (BD Biosciences) version 3.1 software package (5) or FCSPress (Cambridge, United Kingdom).

Enrichment of macrophage populations using magnetic beads. Liver leukocytes were pooled, suspended at $\leq 1 \times 10^{7}$ cells $/ \mathrm{ml}$, and blocked with $2.4 \mathrm{G} 2$ antibody. To specifically enrich for migrating macrophages (21), cells were stained with FITC-labeled CD11b (BD PharMingen) and PE-F4/80 (Serotec). The CD11b ${ }^{+}$cells were enriched using MultiSort anti-FITC microbeads and positive selection columns followed by MultiSort Release Reagent as described by the manufacturer (Miltenyi Biotec GmbH, Bergisch Gladbach, Germany). After separation, positive selection for $\mathrm{PE}-\mathrm{F} 4 / 80^{+}$cells was performed using anti-PE magnetic beads and columns (Miltenyi Biotec $\mathrm{GmbH}$ ). F4/80 ${ }^{+} \mathrm{CD} 11 \mathrm{~b}^{+}$cells were enriched by more than $90 \%$.

Cytokine analyses. Samples of liver homogenates and liver leukocyte-CM were tested for MIP- $1 \alpha$ or IFN- $\alpha$ by ELISA. MIP- $1 \alpha$ was detected using a commercial sandwich ELISA kit as recommended by the manufacturer (R\&D Systems Inc., Minneapolis, Minnesota, USA). IFN- $\alpha$ was detected using a rat anti-mouse IFN- $\alpha$ mAb (F-18; HyCult biotechnology b.v., Uden, The Netherlands) as described (22).

Histology and immunohistochemistry. Liver sections were prepared, stained with hematoxylin and eosin $(H \& E)$, and analyzed microscopically (1). For immunohistochemical analyses, sections were blocked, and IFN- $\alpha / \beta$ protein was detected as described (22). Images were collected digitally with a Roper Scientific Photometrics CoolSNAP Camera System (Roper Scientific Inc., Trenton, New Jersey, USA) and processed using Adobe Photoshop (Adobe Systems Inc., Mountain View, California, USA).

In vivo trafficking assays. Bone marrow leukocytes were isolated and labeled with the red fluorescent dye 
PKH26 (Sigma-Aldrich) $(1,16)$. Labeled cells were delivered intravenously and localized in livers of recipient mice 24 hours after transfer. Liver sections were prepared as described (1), mounted with VECTASHIELD (Vector Laboratories Inc., Burlingame, California, USA) and observed using a Microphot-SA microscope (Nikon, Tokyo, Japan) $(1,16)$. Cells in liver sinusoids were quantitated by counting fluorescent cells in defined areas of representative liver tissues at $\times 100$ magnification. Images were collected digitally with a Spot RT slider camera from Diagnostic Instruments Inc. (Sterling Heights, Michigan, USA) and processed using Adobe Photoshop.

Statistical analyses. Statistical significance of experimental results was analyzed by two-tailed Student's $t$ test where indicated.

\footnotetext{
Results

Liver NK cell accumulation during MCMV infection. NK cells accumulate and localize in liver inflammatory foci during MCMV infections of C57BL/ 6 mice $(1,23)$. To characterize NK cell accumulation in another strain of mice, H\&E-stained liver sections were prepared from C57BL/6 and 129 mice that were uninfected or infected with MCMV for 48 hours. The focal clustering of nucleated cells between portal areas and central veins typical of NK cell inflammation was observed following infections in both strains (Figure 1, a and b). To quantitate the NK cell yields (NK1.1 ${ }^{+}$TCR- $\beta^{-}$or DX5 ${ }^{+}$TCR- $\left.\beta^{-}\right)$in this compartment, leukocytes were prepared, and NK cell proportions and numbers were determined using flow cytometric and total cell recovery. The liver leukocyte yields increased following infection to $4 \times 10^{6} \pm 3 \times 10^{5}$ from the uninfected values of $2 \times 10^{6} \pm 2 \times 10^{5}$ in C57BL/ 6 mice, and to $3 \times 10^{6} \pm 4 \times$ $10^{5}$ from the uninfected values of $1 \times 10^{6} \pm 1 \times 10^{5}$ in 129 mice. Although liver NK cell percentages and yields were higher in C57BL/6 mice, both C57BL/6 and 129
}

mice demonstrated twofold increases in frequencies (Figure 1, c and e) and fourfold increases in absolute numbers (Figure 1, d and f). Thus, both strains exhibit similar liver histological characteristics and induced accumulation of $\mathrm{NK}$ cells during infection.

Induction of IFN- $\alpha / \beta$ protein in liver. As IFN- $\alpha / \beta$ can have profound effects on cell trafficking (13-16) and on cytokines and chemokines $(11,12)$, liver IFN- $\alpha / \beta$ expression was examined by immunohistochemistry. Tissue sections were prepared from uninfected or MCMV-infected C57BL/6 (Figure 2, a-c) or 129 (Figure $2, d-f)$ mice. IFN- $\alpha / \beta$ was not detected in uninfected mice (Figure 2, a and d). However, at 36 and 48 hours after challenge, production was dramatically induced in both strains. Positive cells were detected in sinusoids and as scattered populations within parenchyma (Figure 2, b, c, e, and f). To quantitate type 1 IFN proteins, ELISA assays measuring IFN- $\alpha$ were performed on liver homogenates. At 36 hours, C57BL/ 6 mice had IFN- $\alpha$ values of $66 \pm 3$ and 129 mice had values of $67 \pm 17 \mathrm{ng} / \mathrm{g}$ liver. At 48 hours after infection, C57BL/ 6 mice had $44 \pm 12$ and 129 mice had $64 \pm 5 \mathrm{ng} / \mathrm{g}$ liver. IFN- $\alpha$ was below the limit of detection $(<7 \mathrm{ng} / \mathrm{g}$ liver $)$ in uninfected mice. Taken together, these results demonstrate that both strains produce IFN- $\alpha / \beta$ in liver during MCMV infection.

$I F N-\alpha / \beta$ deficiency and resistance to $M C M V$ infection. To determine the effects of IFN- $\alpha / \beta$ responses for antiviral defense, H\&E-stained liver sections were prepared from mice deficient in IFN- $\alpha / \beta$-mediated functions (IFN$\left.\alpha / \beta R^{-}\right)$and infected with MCMV for 48 or 72 hours. In contrast to immunocompetent (IFN- $\alpha / \beta \mathrm{R}^{+}$) mice (Figure $1 \mathrm{~b}$ ), there was a profound inhibition of inflammatory foci in liver from IFN- $\alpha / \beta R^{-}$mice at both 48 (Figure $3 \mathrm{a}$ ) and 72 (Figure $3 \mathrm{~b}$ ) hours after infection. Cells having the morphological characteristics of MCMV infection, i.e., cytomegalic inclusion bodies, were frequently seen at 48 hours and were readily visible, along with necrotic

\section{Figure 1}

NK cell accumulation in MCMV-infected C57BL/ 6 and 129 livers. Livers were harvested and $\mathrm{H} \& \mathrm{E}$-stained tissue sections were prepared from C57BL/6 (a) or 129 (b) mice infected with MCMV for 48 hours as described in Methods. Arrows in $\mathbf{a}$ and $\mathbf{b}$ denote inflammatory foci. Images were digitally captured at the original magnifications of $\times 10$. Scale bar $=100$ $\mu \mathrm{m}$. (c-f) Liver leukocytes were prepared from C57BL/6 (c and d) or 129 (e and $\mathbf{f}$ ) mice that were uninfected ( 0 hours) or infected with MCMV for 48 hours. Leukocytes were analyzed by flow cytometry as described in Methods. Both the percentage ( $\mathbf{c}$ and $\mathbf{e}$ ) and number ( $\mathbf{d}$ and $\mathbf{f}$ ) of NK1. $1^{+}$TCR- $\beta^{-}$or DX5 $5^{+}$TCR- $\beta^{-}$cells per $g$ liver are shown. Data are the means \pm SE $(n=3-6)$. Differences between uninfected and infected mice are significant at ${ }^{*} P \leq 0.03$ and ${ }^{*} P<0.001$.
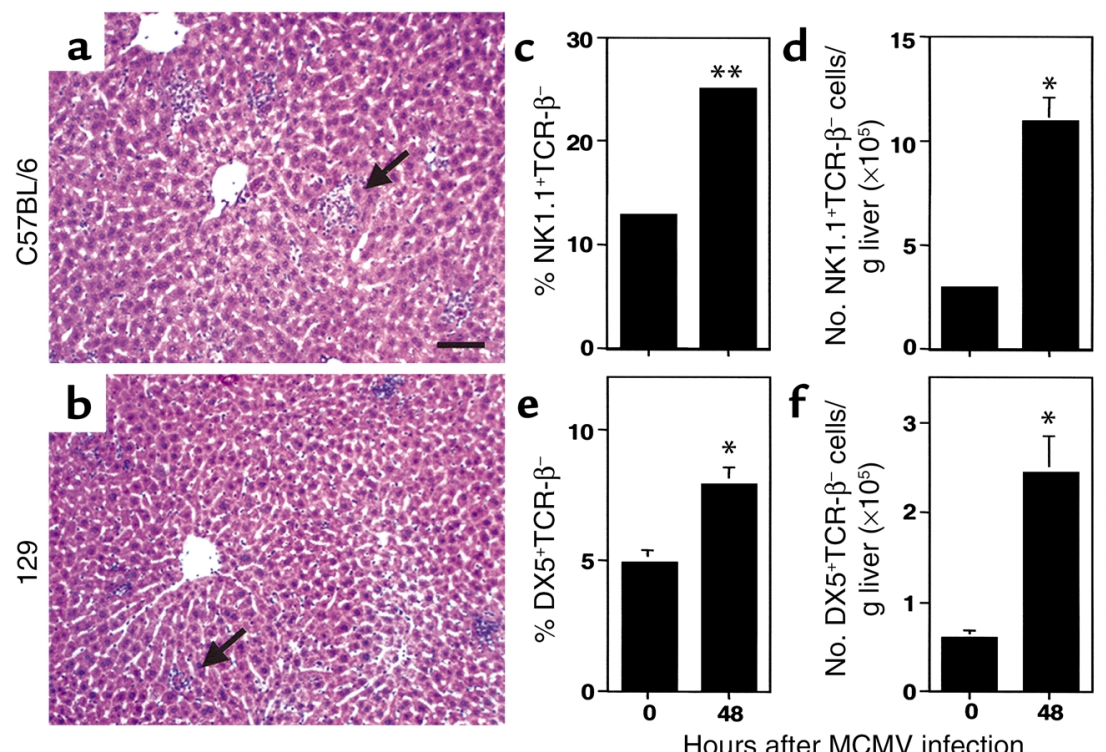

Hours after MCMV infection 


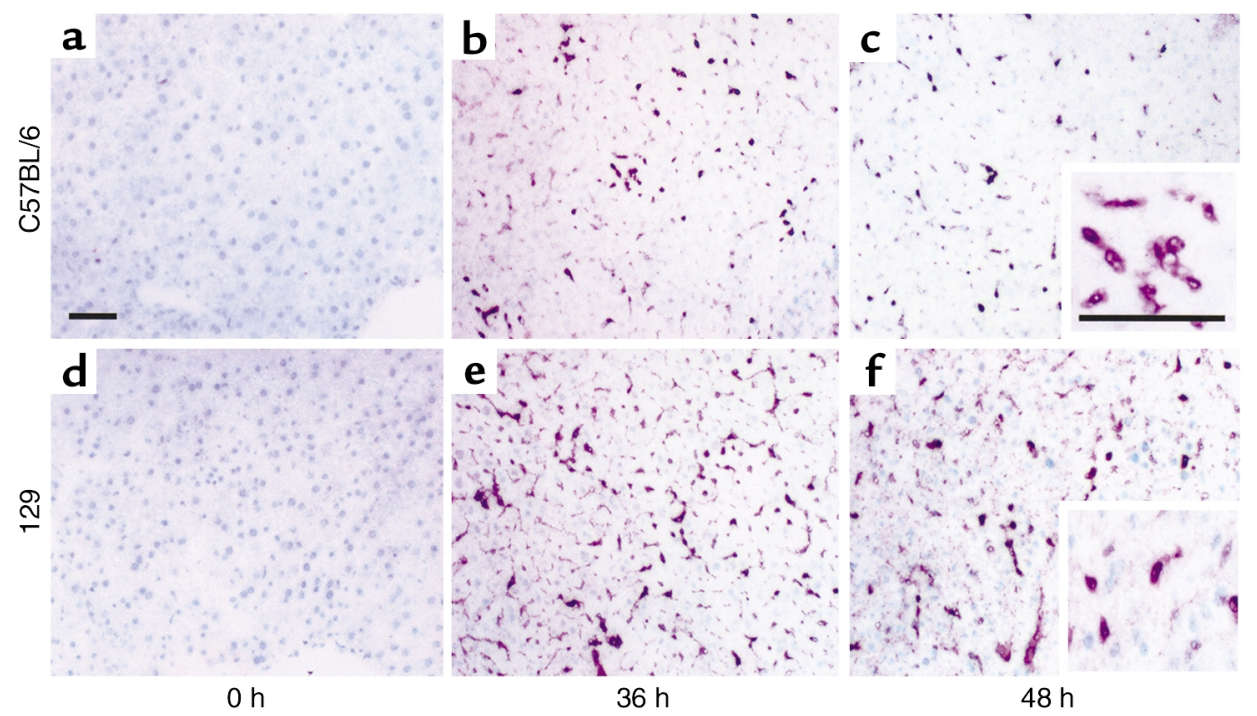

Figure 2

Induction of IFN- $\alpha / \beta$ protein expression in MCMV-infected livers. Organs were harvested from C57BL/ 6 and 129 mice that were uninfected ( 0 hours) or infected with MCMV for 36 or 48 hours. Tissue sections were prepared, immunostained, and counterstained with methyl green as described in Methods. Results shown are from uninfected C57BL/6 (a) and 129 (d) mice, C57BL/6 mice after 36 (b) or 48 (c) hours' infection, and 129 mice after 36 (e) or 48 (f) hours of infection. Insets represent positive cells at a higher magnification. Images were digitally captured at the original magnifications of $\times 10$ and $\times 40$. Scale bars $=100 \mu \mathrm{m}$.

foci, at 72 hours after infection (Figure 3 , a and $b$ ). Thus, virus-induced liver pathology was elevated in the absence of IFN- $\alpha / \beta$-mediated functions. To further examine the importance of IFN- $\alpha / \beta$ for antiviral defense, IFN- $\alpha / \beta \mathrm{R}^{+}$ and IFN- $\alpha / \beta \mathrm{R}^{-}$mice were infected with a lower dose $\left(1 \times 10^{4} \mathrm{PFU}\right)$ of MCMV and monitored for survival. All of the IFN- $\alpha / \beta \mathrm{R}^{-}$, but none of the IFN- $\alpha / \beta \mathrm{R}^{+}$, mice succumbed to infection by day 5 (Figure $3 \mathrm{c}$ ). Therefore, under both moderate- and low-dose conditions of infection the absence of IFN- $\alpha / \beta$-mediated functions profoundly increases susceptibility to MCMV.

$I F N-\alpha / \beta$ effects on NK cell infiltrates and MIP- $1 \alpha$ induction in response to infection. NK cell inflammation is important in promoting defense against MCMV in liv- ers, and our previous studies have shown the critical role of MIP- $1 \alpha$ for this response $(1,5)$. To evaluate the effects of IFN- $\alpha / \beta$ on NK cell accumulation, liver leukocytes were prepared and analyzed from IFN$\alpha / \beta \mathrm{R}^{+}$and IFN- $\alpha / \beta \mathrm{R}^{-}$mice that were uninfected or infected with MCMV for 48 hours. Although liver NK cell frequencies were equivalent in both IFN- $\alpha / \beta \mathrm{R}^{+}$and IFN- $\alpha / \beta R^{-}$mice (data not shown), significant differences in NK cell numbers were evident under both moderate-dose (Figure 4a) and low-dose (Figure 4c) conditions of infection. As total liver leukocyte yields increased, from the uninfected values of 1 to $2 \times 10^{6}$ per $g$ liver to $3.5 \times 10^{6}$ per g liver after moderate-dose and to $4.5 \times 10^{6}$ per g liver after low-dose MCMV infec-
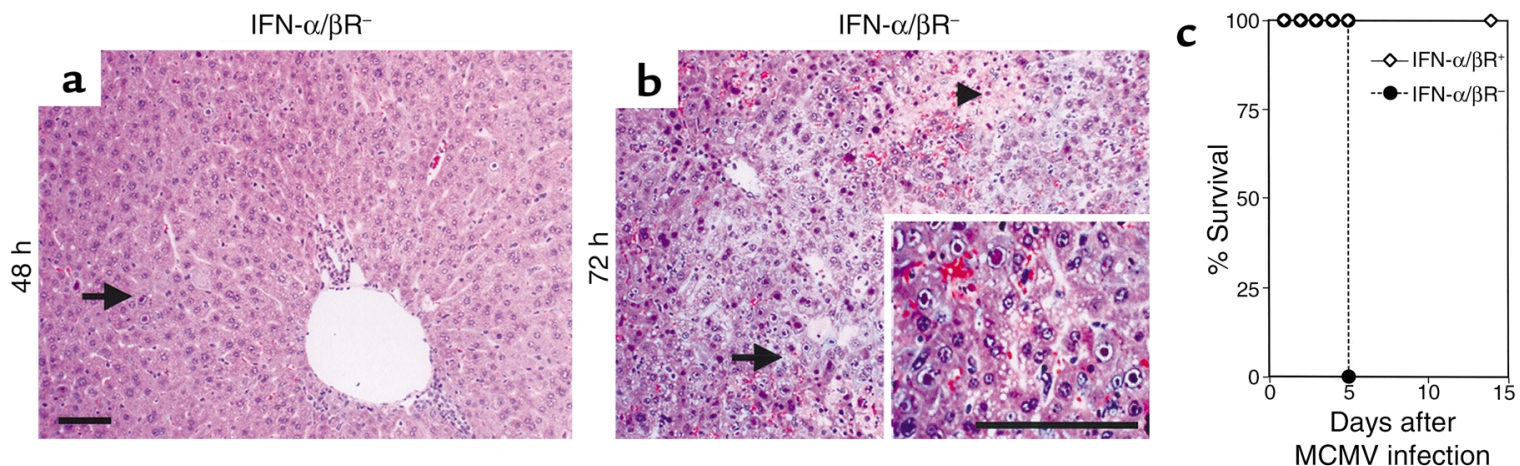

\section{Figure 3}

Effects of IFN- $\alpha / \beta$ on susceptibility to MCMV. Livers were harvested and H\&E-stained sections were prepared from $129-$ IFN- $\alpha / \beta R^{-}$mice infected with $5 \times 10^{4}$ PFU MCMV for 48 (a) or 72 (b) hours. Arrows denote a liver area with cytomegalic inclusion bodies, and the arrowhead in $\mathbf{b}$ represents an area of tissue necrosis. The inset shows cytomegalic inclusion bodies at a higher magnification. Images were digitally captured at the original magnifications of $\times 10$ and $\times 40$. Scale bars $=100 \mu \mathrm{m}$. (c) The $129-\mathrm{IFN}-\alpha / \beta \mathrm{R}^{+}$and $129-\mathrm{IFN}-\alpha / \beta \mathrm{R}^{-}$mice were uninfected or infected with $1 \times 10^{4}$ PFU MCMV and monitored twice daily for survival $(n=6)$. 
tion, IFN- $\alpha / \beta \mathrm{R}^{+}$mice had twofold elevations in NK cell numbers induced by challenge (Figure 4 , a and c). In contrast, liver leukocyte yields from IFN- $\alpha / \beta \mathrm{R}^{-}$mice were only $1 \times 10^{6}$ per g liver after moderate-dose and $9 \times 10^{5}$ per g liver after low-dose infection, compared with the uninfected values of $2 \times 10^{6}$ per $g$ liver. As a result, there were twofold reductions in liver NK cell numbers at 48 hours MCMV infection of IFN- $\alpha / \beta \mathrm{R}^{-}$ mice (Figure 4, a and c). Although there were decreases in NK cell numbers in other compartments during infections of the IFN- $\alpha / \beta \mathrm{R}^{-}$mice at the moderate dose, these were not observed during infections at the lower dose (data not shown). Therefore, the reductions in NK cells infiltrating the liver were not a consequence of generalized NK cell deficiencies. Hence, IFN- $\alpha / \beta$ functions can promote accumulation of NK cells in the liver during infection.

To determine whether IFN- $\alpha / \beta$ modified induction of MIP-1 $\alpha$, ELISA assays were performed with liver homogenates prepared from IFN- $\alpha / \beta \mathrm{R}^{+}$or IFN- $\alpha / \beta \mathrm{R}^{-}$ mice that were uninfected or infected with MCMV for 48 hours. Under the conditions of both moderate-dose (Figure 4b) and low-dose (Figure 4d) infection, MIP-1 $\alpha$ production was induced in livers of both groups of mice. The responses observed in IFN- $\alpha / \beta \mathrm{R}^{-}$, however, were dramatically reduced compared with those in infected IFN- $\alpha / \beta \mathrm{R}^{+}$mice (Figure $4, \mathrm{~b}$ and $\mathrm{d}$ ). By comparison to IFN- $\alpha / \beta R^{+}$, IFN- $\alpha / \beta R^{-}$mice had three- to fourfold reductions in the levels of liver MIP- $1 \alpha$ protein under both conditions of moderate- and low-dose infections. Thus, IFN- $\alpha / \beta$ is necessary for initiation of MIP- $1 \alpha$ expression in liver during MCMV infection.

Induction of MIP- $1 \alpha$ and accumulation of NK cells following $r I F N-\alpha$ administration. As demonstrated above, IFN- $\alpha / \beta$-mediated functions are necessary to effectively control virus (Figure 3 ) as well as to promote MIP- $1 \alpha$ induction and NK cell accumulation during infection (Figure 4). To evaluate the immunoregulatory effects of IFN- $\alpha / \beta$ in the absence of secondary effects resulting from increased virus-induced disease, the consequences of treating uninfected mice with rIFN- $\alpha$ were examined. MIP- $1 \alpha$ protein was measured in liver homogenates prepared from vehicle- or rIFN- $\alpha$-treated C57BL/ 6 and 129 mice. The levels of MIP- $1 \alpha$ were low $(0.08 \mathrm{ng} / \mathrm{g}$ liver $)$ in vehicle-treated C57BL/6 and 129 mice (Figure 5, a and c). In contrast, MIP- $1 \alpha$ protein was dramatically induced to values of $0.5 \mathrm{ng} / \mathrm{g}$ liver in C57BL/6 and $0.2 \mathrm{ng} / \mathrm{g}$ liver in 129 mice after rIFN- $\alpha$ administration (Figure 5, a and c). Thus, rIFN- $\alpha$ exposure result in greater than two- to sixfold inductions of MIP- $1 \alpha$ in livers.

To examine the contribution of rIFN- $\alpha$ to NK cell accumulation, liver leukocytes were prepared and analyzed. Mice receiving rIFN- $\alpha$ had two- to threefold increases in the proportions of NK cells when compared with mice receiving vehicle treatments (data not shown). In both C57BL/6 and 129 mice, the NK cell numbers increased from the vehicle-treated values of $7 \times 10^{4}$ per $\mathrm{g}$ liver to rIFN- $\alpha$-treated values of $2 \times 10^{5}$ per g liver
(Figure 5, b and d). Therefore, rIFN- $\alpha$ elicited a threefold amplification of NK cell yields in liver. Taken together, these results show that rIFN- $\alpha$ treatment promotes both MIP- $1 \alpha$ production and accumulation of liver NK cells even in the absence of virus infection.

Requirement for MIP-1 $\alpha$ in the rIFN- $\alpha$ induction of NK cell accumulation. To demonstrate the role of rIFN- $\alpha$ induction of MIP- $1 \alpha$ in NK cell liver accumulation, the response was evaluated in MIP- $1 \alpha^{+}$and MIP- $1 \alpha^{-}$mice treated with vehicle or rIFN- $\alpha$. Compared with vehicletreated mice, MIP- $1 \alpha^{+}$mice demonstrated twofold increases in total cell yields $\left(3 \times 10^{6}\right.$ to $7 \times 10^{6}$ per g liver) and proportions of NK cells (11\% to $19 \%$ ) after rIFN- $\alpha$ treatment. In contrast, these parameters were not significantly affected after rIFN- $\alpha$ treatment of MIP- $1 \alpha^{-}$mice. Consequently, NK cell numbers were profoundly elevated in MIP- $1 \alpha^{+}$mice from $3 \times 10^{5}$ per $g$ liver after vehicle treatment to $1 \times 10^{6}$ per g liver after rIFN- $\alpha$ administra-
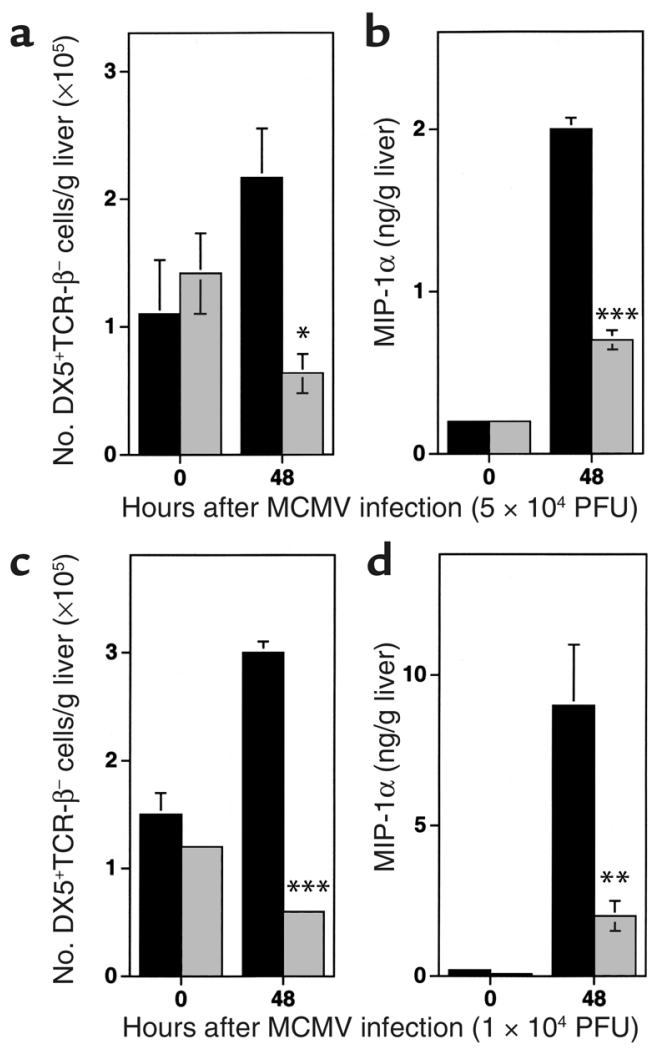

\section{Figure 4}

Effects of IFN- $\alpha / \beta$ functions on MIP- $1 \alpha$ production and NK cell accumulation during MCMV infection. Samples were prepared from 129IFN- $\alpha / \beta R^{+}$(black bars) and $129-I F N-\alpha / \beta R^{-}$(gray bars) mice that were uninfected or infected with $5 \times 10^{4} \mathrm{PFU}$ (moderate dose) (a and $\mathbf{b}$ ) or $1 \times 10^{4} \mathrm{PFU}$ (low dose) (c and d) MCMV for 48 hours. Liver leukocytes were harvested and analyzed by flow cytometry as described in Methods. Numbers of DX $5^{+}$TCR- $\beta-$ NK cells per g liver are shown ( $\mathbf{a}$ and $\mathbf{c}$ ). Data represent the means $\pm \mathrm{SE}(n=3-6)$. Liver homogenates were prepared from the IFN- $\alpha / \beta \mathrm{R}^{+}$or IFN- $\alpha / \beta \mathrm{R}^{-}$mice that were uninfected or infected with moderate-dose (b) or low-dose (d) MCMV for 48 hours. MIP- $1 \alpha$ protein was measured by ELISA. The levels of detection were $0.06-0.08 \mathrm{ng} / \mathrm{g}$ liver. Means $\pm \mathrm{SE}$ are shown $(n=3-6$ mice tested individually). Differences between control IFN- $\alpha / \beta \mathrm{R}^{+}$and IFN- $\alpha / \beta \mathrm{R}^{-}$are significant at ${ }^{*} P \leq 0.03,{ }^{*} P \leq 0.01$, and ${ }^{*} * P<0.0001$. 

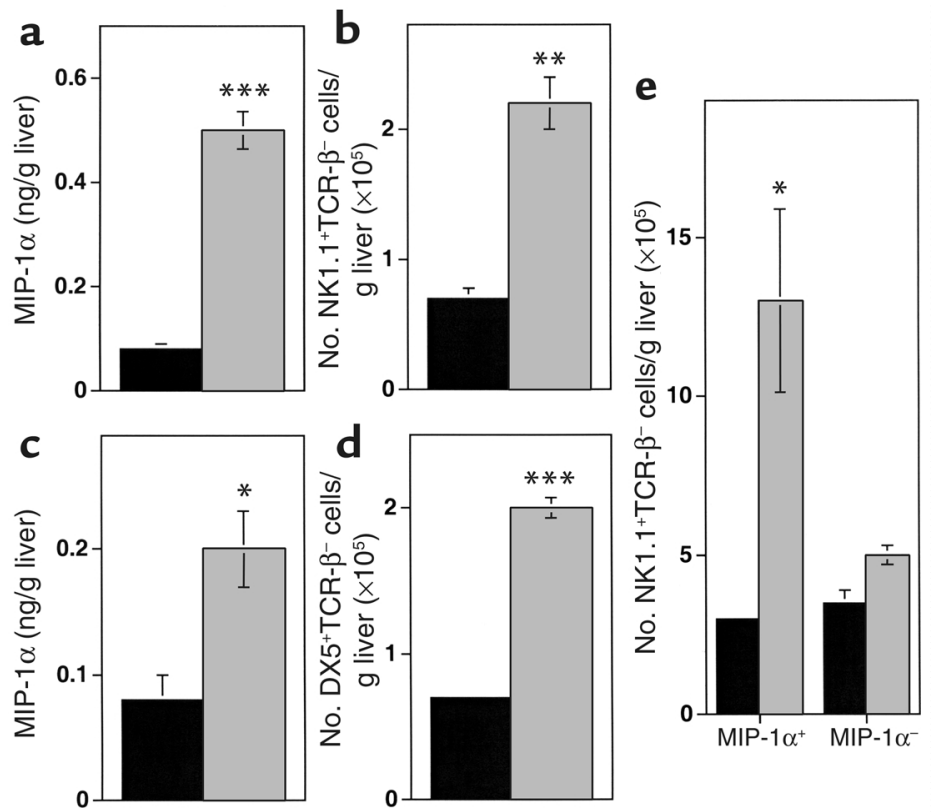

\section{Figure 5}

MIP- $1 \alpha$ induction and NK cell accumulation after treatments with rIFN- $\alpha$. Liver homogenates or liver leukocytes were prepared from C57BL/6 (a and b), 129 (c and d), or C57BL/ $6 \mathrm{MIP}-1 \alpha^{+}$and C57BL/ $6 \mathrm{MIP}-1 \alpha^{-}(\mathbf{e})$ mice treated with vehicle (black bars) or with rIFN- $\alpha$ (gray bars) as described in Methods. MIP- $1 \alpha$ protein was measured in liver homogenates by ELISA (a and $\mathbf{c}$ ). The levels of detection were $0.014 \mathrm{ng} / \mathrm{g}$ liver. Data represent the means \pm SE ( $n=4-8$ mice tested individually). Liver leukocytes were analyzed by flow cytometry as described in Methods. Numbers (b, $\mathbf{d}$, and $\mathbf{e})$ of NK1. $1^{+}$TCR- $\beta^{-}$and DX5+TCR- $\beta$ - NK cells per $g$ liver are shown. Data represent the means \pm SE $(n=4-8)$. Differences between vehicle control and rIFN- $\alpha$ treatments are significant at ${ }^{*} P<0.03,{ }^{*} P \leq 0.01$, and ${ }^{*} * P \leq 0.001$. tion, whereas the NK cell numbers for vehicle- and rIFN$\alpha$-treated MIP- $1 \alpha^{-}$mice remained comparable (Figure $5 e)$. Hence, MIP- $1 \alpha$ is required for the IFN- $\alpha / \beta$-induced accumulation of NK cells in liver.

IFN- $\alpha / \beta$ induction of liver MIP- $1 \alpha$ via cell delivery pathways during infection. Studies were conducted evaluating the requirement for cytokine function in trafficking of bone marrow-derived cells to liver and the contribution of these trafficking populations to liver MIP- $1 \alpha$ production. Cells were fluorescently labeled with PKH26 and intravenously transferred into uninfected or MCMV-infected MIP- $1 \alpha^{-}$recipient mice. Bone marrow populations isolated from uninfected mice were used for cell transfers. Donor cells for analyses were prepared from untreated IFN- $\alpha / \beta R^{+}$or IFN- $\alpha / \beta R^{-}$ mice, and transferred into MIP- $1 \alpha^{-}$recipient mice that were uninfected or infected with MCMV for 24 hours. Livers were harvested at 24 hours after cell transfer, i.e., 48 hours after MCMV infection. Samples were sectioned and analyzed by fluorescent microscopy, or homogenates were prepared, to measure MIP- $1 \alpha$ production. Donor-derived cells were visible in sinusoidal cavities surrounding hepatocytes in both uninfected (Figure 6a) and infected (Figure 6, b and c) MIP-1 $\alpha$ recipient mice. Although trafficking to these areas was observed in all sections, donor cell populations isolated from IFN- $\alpha / \beta \mathrm{R}^{+}$and transferred into infected mice (Figure 6, b and e) demonstrated a threefold induction in localized cells when compared with IFN- $\alpha / \beta \mathrm{R}^{+}$cells transferred into uninfected (Figure 6 , a and $d$ ), or IFN$\alpha / \beta R^{-}$cells transferred into infected (Figure $6, c$ and $f$ ), MIP- $1 \alpha^{-}$recipients (Table 1 ). Thus, the trafficking of bone marrow-derived cells to the liver is induced in response to infection and dependent upon the ability of trafficking cells to respond to IFN- $\alpha / \beta$ effects.

Liver homogenates were prepared from all of the MIP- $1 \alpha^{-}$recipient mice to evaluate production of
MIP- $1 \alpha$ by trafficking cells. The chemokine was only detected in the samples from infected mice receiving bone marrow-derived cells from IFN- $\alpha / \beta \mathrm{R}^{+}$mice (Table $1)$. In contrast, MIP- $1 \alpha$ protein levels in samples from MCMV-infected recipient mice with localized donor cells from IFN- $\alpha / \beta \mathrm{R}^{-}$mice were below the limit of detection (Table 1). Likewise, samples from all uninfected mice were also below the limit of detection. Because the MIP- $1 \alpha$ had to come from the donor cells in these experiments, the results demonstrate that IFN- $\alpha / \beta$ can enhance local MIP- $1 \alpha$ production by promoting recruitment of MIP- $1 \alpha$-producing cells.

IFN- $\alpha / \beta$ effects on macrophage trafficking and accumulation. As macrophages can localize in liver (1), experiments were performed to evaluate the roles of IFN- $\alpha / \beta$ functions for trafficking and accumulation of macrophages. Macrophages are F4/80-positive, and immigrating macrophage populations are defined by expression of both F4/80 and CD11b (21). Donor bone marrow-derived cells were prepared from untreated IFN- $\alpha / \beta \mathrm{R}^{+}$or IFN- $\alpha / \beta \mathrm{R}^{-}$mice, fluorescently labeled with PKH26, and transferred intravenously into IFN$\alpha / \beta R^{+}$or IFN- $\alpha / \beta R^{-}$recipient mice treated with either vehicle or $r I F N-\alpha$. Livers were harvested at 24 hours after cell transfer. Samples were sectioned and analyzed by fluorescent microscopy. Alternatively, liver leukocytes were prepared and analyzed for expression of F4/80 and CD11b to determine the numbers of donorderived macrophages using flow cytometric and cell yield analyses. Donor-derived cells were evident in liver sinusoids from all samples (Figure 7, a-d). However, the transfer of cells from IFN- $\alpha / \beta \mathrm{R}^{+}$into rIFN- $\alpha$-treated IFN- $\alpha / \beta R^{+}$mice (Figure $7 \mathrm{a}$ ) demonstrated a fivefold induction in number of total and a three- to fivefold induction in the number of macrophage donor-derived populations (Figure $7 \mathrm{e}$ ) as compared with transfers into IIFN- $\alpha$-treated IFN- $\alpha / \beta \mathrm{R}^{-}$or vehicle-treated IFN- $\alpha / \beta \mathrm{R}^{+}$ 

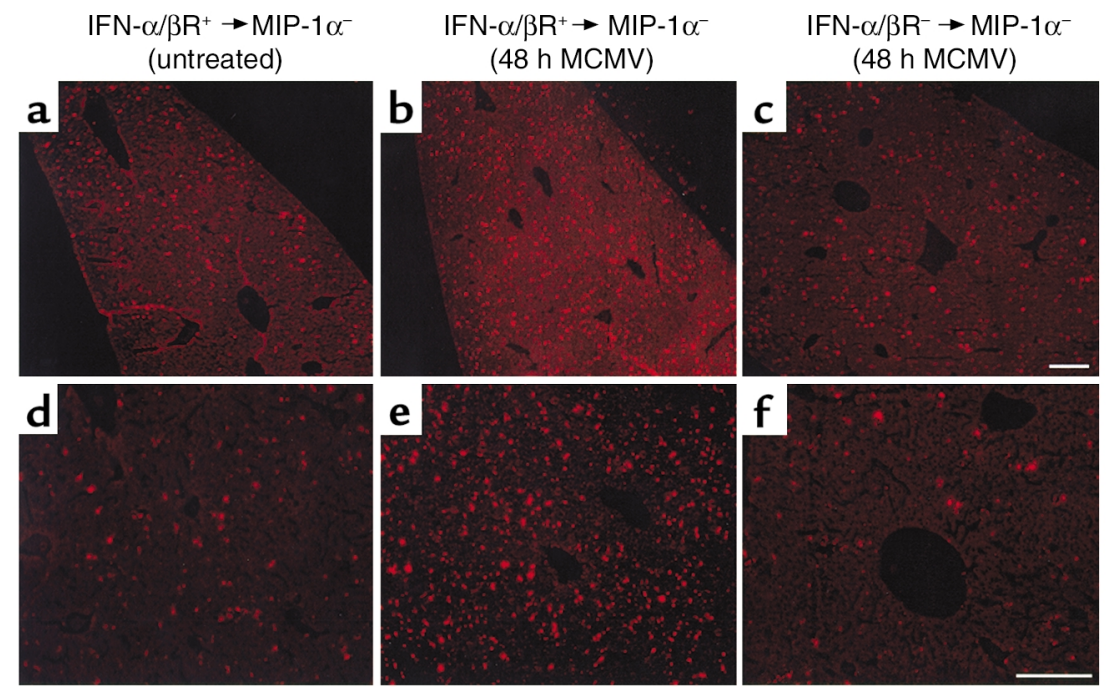

\section{Figure 6}

Characterization of IFN- $\alpha / \beta$-mediated leukocyte trafficking to livers. Bone marrow leukocytes were harvested from uninfected $129-\mathrm{IFN}-\alpha / \beta \mathrm{R}^{+}$ and $129-\mathrm{IFN}-\alpha / \beta \mathrm{R}^{-}$mice and fluorescently labeled as described in Methods. Cells were transferred intravenously to C57BL/6-MIP-1 $\alpha^{-}$recipient mice that were uninfected or infected with MCMV for 24 hours. Livers were harvested 24 hours after cell transfer, processed, sectioned, and examined by fluorescence microscopy. Sections shown are from an uninfected MIP- $1 \alpha^{-}$recipient after transfer of cells from uninfected IFN- $\alpha / \beta R^{+}$donor mice (a and $\mathbf{d}$ ); an MIP- $1 \alpha^{-}$recipient infected with MCMV for 48 hours, after transfer of cells from uninfected IFN- $\alpha / \beta \mathrm{R}^{+}$ donor mice ( $\mathbf{b}$ and $\mathbf{e}$ ); and an MIP- $1 \alpha^{-}$recipient infected with MCMV for 48 hours, after transfer of cells from IFN- $\alpha / \beta R^{-}$mice (c and $\left.\mathbf{f}\right)$. Images were digitally captured at the original magnifications of $\times 10(\mathbf{a}-\mathbf{c})$ and $\times 20(\mathbf{d}-\mathbf{f})$. Scale bars $=100 \mu \mathrm{m}$.

mice (Figure 7, $\mathrm{b}$ and e). In contrast, donor cells isolated from IFN- $\alpha / \beta \mathrm{R}^{-}$and transferred into rIFN- $\alpha$-treated IFN- $\alpha / \beta \mathrm{R}^{+}$(Figure $7 \mathrm{c}$ ) or IFN- $\alpha / \beta \mathrm{R}^{-}$mice (Figure $7 \mathrm{~d}$ ) were limited in their ability to migrate into liver. The number of total and macrophage donor-derived cells did not change significantly when compared with those isolated from IFN- $\alpha / \beta \mathrm{R}^{+}$and transferred into vehicletreated IFN- $\alpha / \beta \mathrm{R}^{+}$(Figure $7 \mathrm{e}$ ) mice. Thus, the results demonstrate that IFN- $\alpha / \beta$-mediated effects on both donor and recipient populations promote the migration of macrophages into livers.

To determine the effects of IFN- $\alpha / \beta$ on overall macrophage accumulation, the proportions and numbers of $\mathrm{F} 4 / 80^{+} \mathrm{CD} 11 \mathrm{~b}^{+}$cells were determined in liver leukocyte populations after either rIFN- $\alpha$ treatment or MCMV infection. Following administration of rIFN- $\alpha$, the frequency of $\mathrm{F} 4 / 80^{+}$cells, and that of $\mathrm{F} 4 / 80^{+}$cells also expressing CD11b, were elevated twofold after
rIFN- $\alpha$ as compared with those in mice receiving vehicle treatments (Figure 7f). The immigrating macrophage cell numbers increased from the vehicle-treated values of $1 \times 10^{4}$ to $5 \times 10^{4}$ per g liver (Figure $7 \mathrm{~g}$ ). Under the conditions of either moderate-dose (Figure $8 \mathrm{a}$ ) or low-dose (Figure 8b) MCMV infections, the frequencies of $\mathrm{F} 4 / 80^{+}$cells increased approximately twofold and the frequencies of those also expressing CD11b increased to $83-87 \%$ from the uninfected values of $53-65 \%$ in IFN- $\alpha / \beta \mathrm{R}^{+}$mice. As the infection-induced total liver leukocyte numbers increased to $2 \times 10^{6}$ per $g$ liver after moderate dose and $3 \times 10^{6}$ per $g$ liver after low dose from the uninfected values of $1 \times 10^{6}$ per $g$ liver, IFN- $\alpha / \beta \mathrm{R}^{+}$mice had more-than-fivefold elevations in immigrating macrophage cell numbers at 48 hours after infection (Figure 8, a and b). In contrast, although the frequencies of $\mathrm{F} 4 / 80^{+}$cells did increase in infected IFN- $\alpha / \beta \mathrm{R}^{-}$mice, the frequencies of $\mathrm{F} 4 / 80^{+}$cells

\section{Table 1}

IFN- $\alpha / \beta$ requirement for MIP-1 $\alpha$ production and cell trafficking to sinusoidal areas in MCMV-infected liver

\begin{tabular}{|c|c|c|c|c|}
\hline Donor $\rightarrow$ Recipient & $\begin{array}{l}\text { Treatment } \\
\text { Donor }\end{array}$ & Recipient & $\begin{array}{c}\text { Number of fluorescent } \\
\text { sinusoidal cells per liver area }\end{array}$ & $\begin{array}{l}\text { MIP-1 } \alpha \text { production } \\
(\mathrm{pg} / \mathrm{g} \text { liver })\end{array}$ \\
\hline $\mathrm{IFN}-\alpha / \beta \mathrm{R}^{+} \rightarrow \mathrm{MIP}-1 \alpha^{-}$ & Uninfected & Uninfected ${ }^{A}$ & $485 \pm 23$ & $\mathrm{BLD}^{\mathrm{A}}$ \\
\hline $\mathrm{IFN}-\alpha / \beta \mathrm{R}^{+} \rightarrow \mathrm{MIP}-1 \alpha^{-}$ & Uninfected & 48 hours MCMV & $1488 \pm 31$ & $22 \pm 1.5$ \\
\hline $\mathrm{IFN}-\alpha / \beta \mathrm{R}^{-} \rightarrow \mathrm{MIP}-1 \alpha^{-}$ & Uninfected & Uninfected ${ }^{A}$ & $344 \pm 4$ & $\mathrm{BLD}^{\mathrm{A}}$ \\
\hline $\mathrm{IFN}-\alpha / \beta \mathrm{R}^{-} \rightarrow \mathrm{MIP}-1 \alpha^{-}$ & Uninfected & 48 hours MCMV & $572 \pm 14^{\mathrm{B}}$ & BLD \\
\hline
\end{tabular}

Bone marrow cells were isolated from donor mice treated as indicated, labeled with PKH26, and intravenously transferred into untreated mice or mice infected with MCMV for 24 hours. Livers were harvested 24 hours after cell transfer and were either processed, sectioned, and analyzed by fluorescence microscopy or used to prepare liver homogenates, as described in Methods. MIP-1 $\alpha$ production was measured in liver homogenates by ELISA. The levels of detection were $1.5 \mathrm{pg} / \mathrm{g}$ liver. Data shown represent the means $\pm \mathrm{SE}\left(n=6\right.$, except $\left.{ }^{\mathrm{A}} n=2\right)$. Number of fluorescent cells localized in sinusoids per 5 -mm ${ }^{2}$ area was counted. BNumber compared with infected control is significantly different, $P<0.000001$. BLD, below the level of detection. 

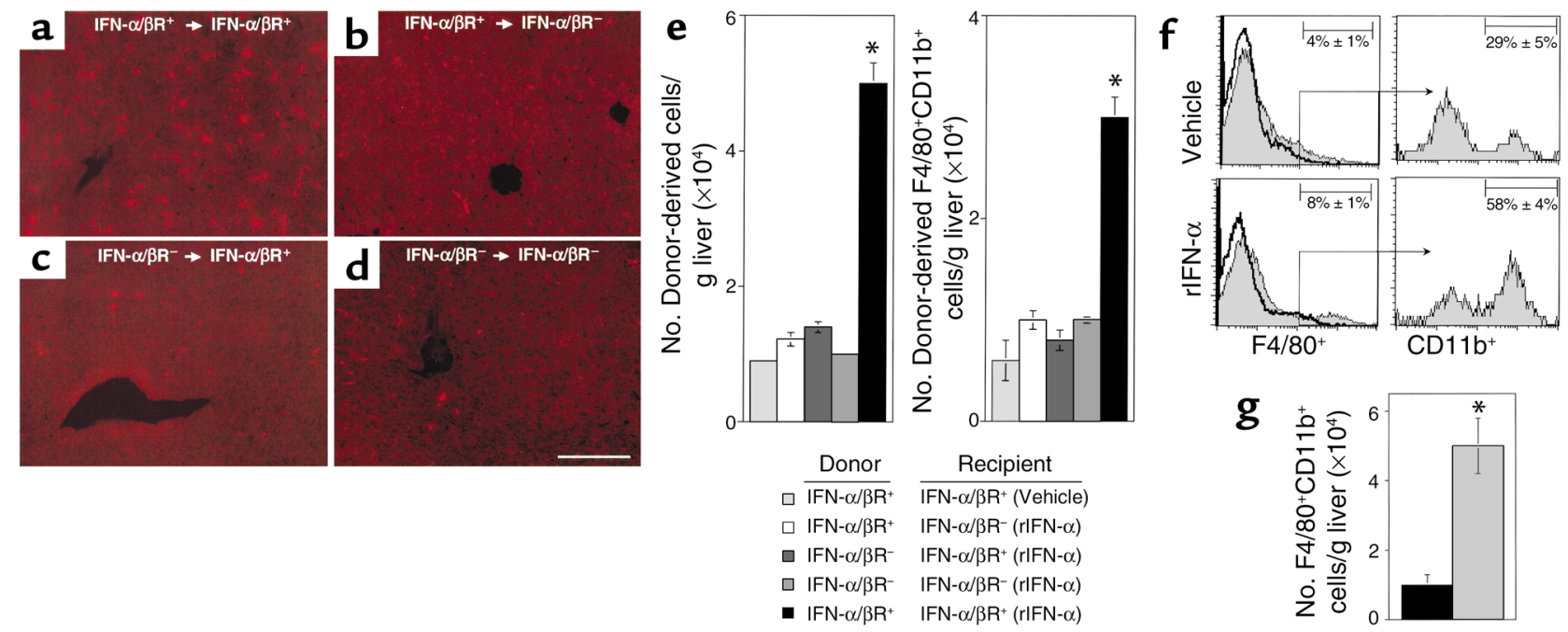

\begin{abstract}
Figure 7
Characterization of macrophage trafficking to and accumulation in livers after rIFN- $\alpha$ treatment. Bone marrow leukocytes from untreated $129-\mathrm{IFN}-\alpha / \beta \mathrm{R}^{+}$or $129-\mathrm{IFN}-\alpha / \beta \mathrm{R}^{-}$mice were fluorescently labeled as described in Methods. Cells were transferred intravenously to IFN- $\alpha / \beta \mathrm{R}^{+}$ or IFN- $\alpha / \beta R^{-}$recipients that were treated with vehicle or rIFN- $\alpha$ and examined. Sections shown are from an rIFN- $\alpha-$ treated IFN- $\alpha / \beta R^{+}$recipient after transfers from untreated IFN- $\alpha / \beta R^{+}$donors $(a)$, an rIFN- $\alpha$-treated IFN- $\alpha / \beta R^{-}$recipient after transfers from untreated IFN- $\alpha / \beta R^{+}$ donors (b), an rIFN- $\alpha$-treated IFN- $\alpha / \beta R^{+}$recipient after transfers from untreated IFN- $\alpha / \beta R^{-}$donors (c), and an rIFN- $\alpha-$ treated IFN- $\alpha / \beta R^{-}$ recipient after transfers from untreated IFN- $\alpha / \beta R^{-}$donors $(\mathbf{d})$. Scale bar $=100 \mu \mathrm{m}$. Liver leukocytes were prepared from recipient mice and analyzed by flow cytometry. Numbers of donor-derived $\mathrm{PKH} 26^{+}$and $\mathrm{PKH} 26^{+} \mathrm{F} 4 / 80^{+} \mathrm{CD} 11 \mathrm{~b}^{+}$cells g liver are shown (e). ${ }^{*}$ Difference between vehicle- and rIFN- $\alpha$-treated IFN- $\alpha / \beta R^{+}$recipients is significant at $P<0.001$. To characterize the accumulation of migrating macrophages, liver leukocytes were obtained from IFN- $\alpha / \beta \mathrm{R}^{+}$or IFN- $\alpha / \beta \mathrm{R}^{-}$mice that were treated with vehicle or rIFN- $\alpha$, labeled with F4/80 and CD11b and examined by flow cytometry. Migrating populations were identified by analyses of $\mathrm{CD} 11 \mathrm{~b}$ expression after gating on the $\mathrm{F} 4 / 80^{+}$cells (f). Representative histograms are shown, with thick lines representing isotype control antibody and shaded histograms F4/80 or CD11b labeling. Percentages of $\mathrm{F} 4 / 80^{+} \mathrm{CD} 11 \mathrm{~b}^{+}$macrophages per $\mathrm{g}$ liver isolated from vehicle- (black bar) or rIFN- $\alpha$-treated (gray bar) samples are shown $(\mathbf{g})$. In all experiments, data represent the means $\pm \mathrm{SE}(n=3)$. ${ }^{*}$ Difference between vehicle control and riFN- $\alpha$ treatments is significant at $P \leq 0.02$.
\end{abstract}

also expressing $\mathrm{CD} 11 \mathrm{~b}$ macrophage populations decreased two- to fourfold (Figure 8, a and b) compared with those in uninfected mice. Moreover, liver leukocyte yields from IFN- $\alpha / \beta R^{-}$mice were only $9 \times 10^{5}$ per $\mathrm{g}$ liver after moderate-dose and $1 \times 10^{6}$ per g liver after low-dose infection, compared with the uninfected values of 1 to $2 \times 10^{6}$ per g liver. Hence, the numbers of immigrating macrophages in IFN- $\alpha / \beta \mathrm{R}^{-}$mice were significantly lower after MCMV infection (Figure 8, a and b). Taken together, these results demonstrate that IFN- $\alpha / \beta$ mediates trafficking and accumulation of macrophages into liver.

Characterization of MIP-1 $\alpha$-producing cells. Macrophages are a known source of MIP-1 $\alpha(1,8)$. To determine whether trafficking macrophages contributed to production of MIP- $1 \alpha$, total liver leukocytes and enriched macrophages were prepared from C57BL/6 (Figure 8c) and 129 (Figure 8d) mice that were uninfected or infected with low-dose MCMV for 48 hours; they were then evaluated for their ability to release the chemokine. Following infection, total populations were induced to produce MIP- $1 \alpha$. However, the levels of MIP- $1 \alpha$ produced by enriched trafficking macrophages, expressing both F4/80 and CD11b, were dramatically elevated over the levels produced by total leukocytes. The macrophages from infected C57BL/6 (Figure 8c) or infected 129 (Fig- ure 8d) mice produced 12 -fold or 22 -fold more MIP- $1 \alpha$ protein, respectively, when compared with total cells. Therefore, migrating macrophages are a major source of MIP- $1 \alpha$ production in liver during MCMV infection.

\section{Discussion}

These studies define a significant role and mechanism of action for IFN- $\alpha / \beta$ in promoting expression of MIP- $1 \alpha$ and the accumulation of NK cells in liver during MCMV infection. They demonstrate that IFN- $\alpha / \beta$ is produced locally and is an important factor in protecting against infection. Immunoregulatory effects are shown to be contributing to IFN- $\alpha / \beta$-mediated defense, since critical production of MIP- $1 \alpha$, required for accumulation of NK cells, is dependent on the functions of these cytokines. The data indicate that IFN- $\alpha / \beta$ is upstream of MIP- $1 \alpha$ induction in liver, and that IFN- $\alpha / \beta$ is promoting local expression of MIP- $1 \alpha$, at least in part, by acting as a recruiter of macrophages producing the chemokine. As these responses are also induced with administrated rIFN- $\alpha$, the cytokines can act in the absence of infection. Taken together, these studies identify IFN- $\alpha / \beta$ as key initiators of MIP- $1 \alpha$ expression required for NK cell recruitment into liver. The results extend our characterization of a critical chemokine-to-cytokine-to-chemokine cascade for 
antiviral defense (5) by defining IFN- $\alpha / \beta$-dependent events upstream of MIP- $1 \alpha$ necessary for initiating this multistep immune process.

IFN- $\alpha / \beta$ can elicit potent antiviral effects and mediate several immunoregulatory activities $(11,12-16)$. The possibility that the loss of direct antiviral effects also contributed to the increased sensitivity of IFN$\alpha / \beta \mathrm{R}^{-}$mice to MCMV infection cannot be excluded (Figure 3). However, we have previously demonstrated that MIP- $1 \alpha$, NK cell delivery of IFN- $\gamma$ to liver, and IFN- $\gamma$ induction of Mig are all critical steps in protection against this virus $(1,5)$. The studies presented here demonstrate that the induction of MIP- $1 \alpha$ in liver is dependent on the immunoregulatory effects mediated by IFN- $\alpha / \beta$, and that these occur in the absence of infections. Thus, these factors are upstream initiators of an essential chemokine-cytokine cascade.

The studies presented here definitively establish the role of IFN- $\alpha / \beta$ in driving the accumulation of macrophages in the liver (Figures 7 and 8 ). The cells are defined as immigrating macrophages by their coexpression of $\mathrm{F} 4 / 80$ and $\mathrm{CD} 11 \mathrm{~b}$. The conditions also promoted the migration of other cell types, since the double positive cells represented fewer than $10 \%$ of the donor-derived cells (Figure 7e). The other trafficking subsets would include NK cells (Figure 5) and may include other leukocyte subsets not yet characterized, i.e., dendritic cells and neutrophils. However, the dou- ble positive populations are greatly enriched for MIP$1 \alpha$-producing cells (Figure 8, $\mathrm{c}$ and $\mathrm{d}$ ). The transfer of IFN- $\alpha / \beta R^{-}$bone marrow cells to infected MIP- $1 \alpha^{-}$mice failed to result in both the dramatic accumulation of macrophages in sinusoids and the appearance of MIP-1 $\alpha$ production in liver (Figure 6 and Table 1). Under these conditions, the effects on cell accumulation are likely to have been a consequence of earlier blocked cellular IFN- $\alpha / \beta$ responsiveness rather than of resulting reductions in MIP- $1 \alpha$ production, since infection-induced migration of macrophages to liver sinusoids is MIP- $1 \alpha$ independent (1). It is not yet clear, however, whether additional chemokine responses are regulated by IFN- $\alpha / \beta$ and/or play an intermediary role in macrophage migration. Macrophages have been shown to produce chemokines in response to various stimuli $(8,24-27)$. Here, immigrant liver macrophages are shown to produce MIP- $1 \alpha$ during infection.

The observations clearly demonstrate that IFN- $\alpha / \beta$ functions are required for MIP- $1 \alpha$ induction during MCMV infection in liver, and that promoting accumulation of macrophages producing MIP- $1 \alpha$ to this site is a contributing mechanism for this. The responses of other innate cytokines, such as IL-12, IL-15, and NK cell-derived IFN- $\gamma$, also are expressed during early MCMV infection (refs. 10, 28; K.B. Nguyen et al., unpublished observations). These factors have been shown to stimulate production of MIP- $1 \alpha$ from cul-

\section{$\mathbf{a}$}
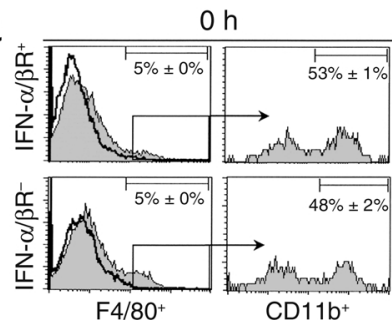

b
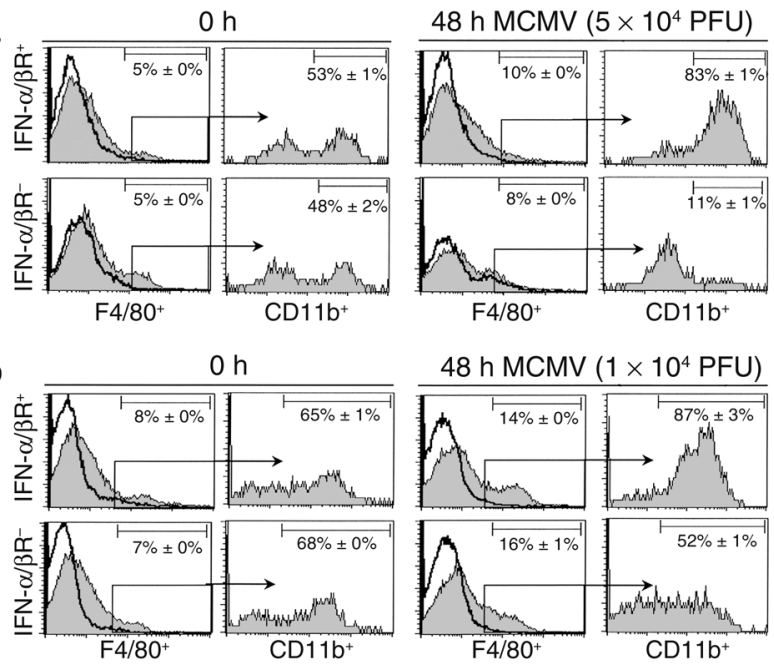
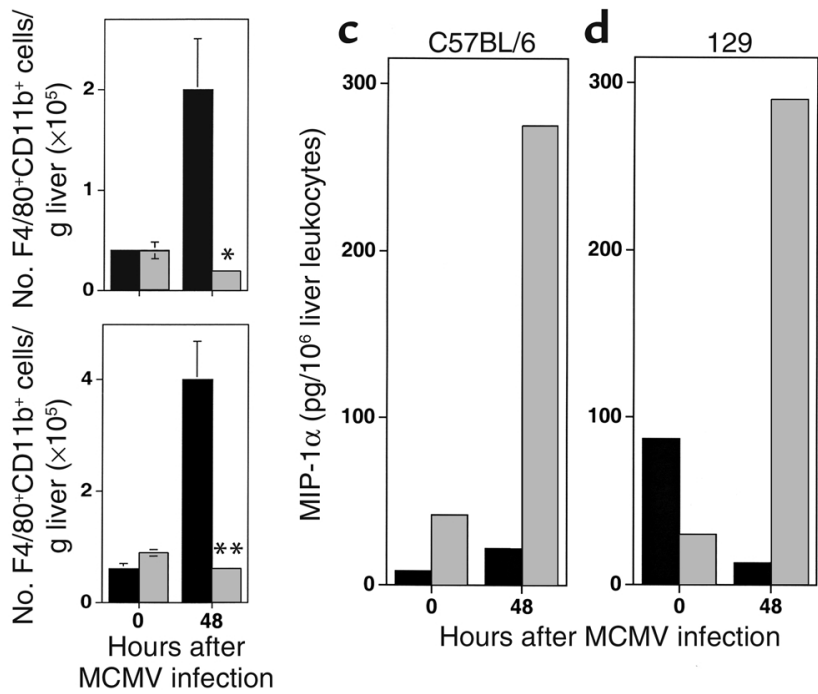

Figure 8

Characterization of IFN- $\alpha / \beta$-mediated effects on macrophage accumulation and of MIP- $1 \alpha$-producing cells in liver during MCMV infection. Liver leukocytes were prepared from $129-\mathrm{IFN}-\alpha / \beta \mathrm{R}^{+}$or 129 -IFN- $\alpha / \beta \mathrm{R}^{-}$mice that were uninfected or infected with moderate-dose (a) or lowdose (b) MCMV for 48 hours. Leukocytes were analyzed by flow cytometry as described in Methods. Macrophages were identified by F4/80 expression and are shown by histograms ( $\mathbf{a}$ and $\mathbf{b})$. The accumulation of migrating populations was subsequently identified by analyses of $\mathrm{CD} 11 \mathrm{~b}$ expression after gating on the $\mathrm{F} 4 / 80^{+}$population and is shown by histograms ( $\mathbf{a}$ and $\left.\mathbf{b}\right)$. The data shown are representative histograms, with thick lines representing isotype control antibody and shaded histograms F4/80 or CD11b labeling. Percentages presented in each histogram are means \pm SE $(n=3-4)$. Numbers of F $4 / 80^{+} C D 11 b^{+}$cells per $g$ liver isolated from $129-I F N-\alpha / \beta R^{+}($black bars $)$or $129-I F N-$ $\alpha / \beta R^{-}$(gray bars) are shown (a and $\left.\mathbf{b}\right)$. Data represent the means \pm SE $(n=3-4)$. Differences between control IFN- $\alpha / \beta R^{+}$and IFN- $\alpha / \beta R^{-}$are significant at ${ }^{*} P \leq 0.03$ and ${ }^{*} P \leq 0.01$. (c and $\mathbf{d}$ ) Total (black bars) or enriched $F 4 / 80^{+} \mathrm{CD} 11 \mathrm{~b}^{+}$(gray bars) liver leukocytes were prepared from C57BL/6 (c) or 129 (d) mice that were uninfected or infected with low-dose MCMV for 48 hours. Leukocyte-CM was used to measure MIP- $1 \alpha$ in ELISA as described in Methods. Levels of detection were $0.2 \mathrm{pg} / \mathrm{million}$ cells. Each group consisted of pooled cell samples from six mice. The data shown are representative of two independent experiments. 
tures of purified human NK cells (29). However, they do not appear to be required for liver MIP- $1 \alpha$ induction during MCMV infection (T.P. Salazar-Mather and C.A. Biron, unpublished observations). The promoter region for murine MIP- $1 \alpha$ does have a potential IFN- $\alpha / \beta$-responsive element $(30,31)$, suggesting a role for this cytokine in enhancing transcription of the chemokine. Our studies do not eliminate the possibility that IFN- $\alpha / \beta$ can directly enhance induction of MIP- $1 \alpha$, but they do undoubtedly demonstrate the presence of another pathway for cell delivery of MIP- $1 \alpha$ to MCMV-infected livers.

In summary, this work has extended our characterization of molecular mechanisms of cellular recruitment required for innate defense against viral infection in liver. Our results identify IFN- $\alpha / \beta$ as key initiators of MIP- $1 \alpha$ production that is necessary for NK cell inflammation. In addition, by showing that IFN- $\alpha / \beta$ can mediate the recruitment of MIP-1 $\alpha$-producing macrophages, our results define a cellular delivery mechanism by which these cytokines promote local immune responses.

\section{Acknowledgments}

The authors wish to thank K.B. Nguyen for expert assistance with flow cytometry, and G. Yap, M. Dalod, and G. Gutierrez for experimental help. This work was supported by NIH grants CA-79076 and CA-41268.

1. Salazar-Mather, T.P., Orange, J.S., and Biron, C.A. 1998. Early murine cytomegalovirus (MCMV) infection induces liver natural killer (NK) cell inflammation and protection through macrophage inflammatory protein $1 \alpha($ MIP-1 $\alpha)$-dependent pathways. J. Exp. Med. 187:1-14.

2. Orange, J.S., Wang, B., Terhorst, C., and Biron, C.A. 1995. Requirement for natural killer cell-produced interferon- $\gamma$ in defense against murine cytomegalovirus infection and enhancement of this defense pathway by interleukin-12 administration. J. Exp. Med. 182:1045-1056.

3. Biron, C.A., Nguyen, K.B., Pien, G.C., Cousens, L.P., and Salazar-Mather, T.P. 1999. Natural killer cells in antiviral defense: function and regulation by innate cytokines. Annu. Rev. Immunol. 17:189-220.

4. Ruzek, M.C., Miller, A.H., Opal, S.M., Pearce, B.D., and Biron, C.A. 1997. Characterization of early cytokine responses and an interleukin (IL)-6dependent pathway of endogenous glucocorticoid induction during murine cytomegalovirus infection. J. Exp. Med. 185:1185-1192.

5. Salazar-Mather, T.P., Hamilton, T.A., and Biron, C.A. 2000. A chemokine-to-cytokine-chemokine cascade critical in antiviral defense. J. Clin. Invest. 105:985-993.

6. Farber, J.M. 1997. Mig and IP10: CXC chemokines that target lymphocytes. J. Leukoc. Biol. 61:246-257.

7. Miura, M., et al. 2001. Monokine induced by IFN-gamma is a dominant factor directing $\mathrm{T}$ cells into murine cardiac allografts during acute rejection. J. Immunol. 167:3494-3504.

8. Rollins, B.J. 1997. Chemokines. Blood. 90:909-928.

9. Rossi, D., and Zlotnick, A. 2000. The biology of chemokines and their receptors. Annu. Rev. Immunol. 18:217-242.

10. Orange, J.S., and Biron, C.A. 1996. Characterization of early IL-12,
IFN- $\alpha / \beta$, and TNF effects on antiviral state and NK cell responses during murine cytomegalovirus infection. J. Immunol. 156:4746-4756.

11. Biron, C.A. 2001. Interferons $\alpha$ and $\beta$ as immune regulators: a new look. Immunity. 14:661-664.

12. Biron, C.A., Dalod, M., and Salazar-Mather, T.P. 2002. Innate immunity and viral infections. In Immunology of infectious diseases. S.H.E. Kaufmann, A. Sher, and R. Ahmed, editors. ASM Press. Washington, DC, USA. $139-160$.

13. Korngold, R., Blank, K.J., and Murasko, D.M. 1983. Effect of interferon on thoracic duct lymphocyte output: induction with either polyI:C or vaccinia virus. J. Immunol. 130:2236-2243.

14. Wiltrout, R.H., et al. 1989. Augmentation of mouse liver-associated natural killer cell activity by biological response modifiers occurs largely via rapid recruitment of large granular lymphocytes from the bone marrow. J. Immunol. 143:372-378.

15. Ishikawa, R., and Biron, C.A. 1993. IFN induction and associated changes in splenic leukocyte distribution. J. Immunol. 150:3713-3727.

16. Salazar-Mather, T.P., and Biron, C.A. 1996. NK cell trafficking and cytokine expression in splenic compartments after IFN induction and viral infection. J. Immunol. 157:3054-3064.

17. Cook, D.N., et al. 1995. Requirement of MIP- $1 \alpha$ for an inflammatory response to viral infection. Science. 269:1583-1585.

18. Muller, U., et al. 1994. Functional role of type 1 and type II interferons in antiviral defense. Science. 264:1918-1921.

19. Pien, G.C., and Biron, C.A. 2000. Compartmental differences in NK cell responsiveness to IL-12 during lymphocytic choriomeningitis virus infection. J. Immunol. 164:994-1001.

20. Arase, H., Saito, T., Phillips, J.H., and Lanier, L.L. 2001. Cutting edge: the mouse NK cell-associated antigen recognized by DX5 monoclonal antibody is $\mathrm{CD} 49 \mathrm{~b}$ ( $\alpha_{2}$ integrin, very late antigen-2). J. Immunol. 167:1141-1144.

21. Lepay, D.A., Steinman, R.M., Nathan, C.F., Murray, H.W., and Cohn, Z.A 1985. Liver macrophages in murine listeriosis. J. Exp. Med. 161:1503-1512.

22. Dalod, M., et al. 2002. IFN- $\alpha / \beta$ and IL-12 responses to viral infections: pathways regulating dendritic cell cytokine expression in vivo. J. Exp. Med. 195:517-528.

23. Andrews, D.M., et al. 2001. NK1.1+ cells and murine cytomegalovirus infection: what happens in situ? J. Immunol. 166:1796-1802.

24. Orange, J.S., and Biron, C.A. 1996. An absolute and restricted requirement for interleukin-12 in natural killer (NK) cell interferon- $\gamma$ production and antiviral defense: studies of NK and T cell responses in contrasting viral infections. J. Immunol. 156:1138-1142.

25. Bluman, E.M., Bartynski, K.J., Avalos, B.R., and Caligiuri, M.A. 1996 Human natural killer cells produce abundant macrophage inflammatory protein- $1 \alpha$ in response to monocyte-derived cytokines. J. Clin. Invest. 97:2722-2727.

26. Fujita, T., Shibuya, H., Hotta, H., Yamanishi, K., and Taniguchi, T. 1987. Interferon-beta gene regulation: tandemly repeated sequences of a synthetic 6 bp oligomer function as a virus-inducible enhancer. Cell. 49:357-367.

27. Widmer, U., Manogue, K.R., Cerami, A., and Sherry, B. 1993. Genomic cloning and promoter analyses of macrophage inflammatory protein (MIP)-2, MIP- $1 \alpha$, and MIP-1 $\beta$, members of the chemokine superfamily of proinflammatory cytokines. J. Immunol. 150:4996-5012.

28. Farber, J.M. 1990. A macrophage mRNA selectively induced by $\gamma$-interferon encodes a member of the platelet 4 family of cytokines. Proc. Natl. Acad. Sci. USA. 87:5238-5242.

29. Oppenheim, J.J., Zachariae, C.O.C., Mukaida, N., and Matsushima, K. 1991. Properties of the novel proinflammatory supergene "intercrine" cytokine family. Annu. Rev. Immunol. 9:617-648.

30. Kopydlowski, K.M., et al. 1999. Regulation of macrophage chemokine expression by lipopolysaccharide in vitro and in vivo. J. Immunol. 163:1537-1544.

31. Lehner, T., et al. 2000. Heat shock protein generates $\beta$-chemokines which function as innate adjuvant enhancing adaptive immunity. Eur. J. Immunol. 30:594-603. 